\title{
O cuidado aos usuários de drogas em situação de privação de liberdade
}

| ${ }^{1}$ Sheila Silva Lima |

Resumo: Este estudo visou identificar o cuidado

1 Universidade Federal da Bahia, Psicologia. Salvador-BA, Brasil ofertado às pessoas que se encontram presas e fazem uso (lima.ssheila@gmail.com). de drogas, bem como as mudanças ocorridas na assistência ORCID: 0000-0002-9376-491X à saúde mental após a publicação do Plano Nacional de Saúde no Sistema Penitenciário e da Política Nacional de Atenção Integral à Saúde das Pessoas Privadas de Liberdade. Foi realizada uma pesquisa bibliográfica, identificando-se 129 artigos, sendo selecionados seis após a aplicação dos testes de relevância. A literatura aponta que é consensual o uso de drogas durante o cumprimento da pena, apesar da predominância do paradigma proibicionista em detrimento das açôes de redução de danos.

> Palavras-chave: usuários de drogas; prisões; saúde mental; políticas públicas. 


\section{Introdução}

Abordar a situação das pessoas que estão em privação de liberdade nas prisôes é bastante complexo e desafiador, seja pelos mitos que circulam acerca daqueles que ali estão encarcerados, os quais são comumente tidos como perigosos e cruéis; seja pelo desinteresse público para com essa população, uma vez que são consideradas pessoas que não mereceriam qualquer tipo de assistência ou benefício - ao contrário, deveriam receber uma puniçáo por seus atos pregressos.

O Brasil ocupa o terceiro lugar no ranking dos países com a maior população carcerária do mundo, contando com cerca de 726 mil pessoas em privação de liberdade, precedido apenas pelos Estados Unidos e a China (NASCIMENTO; BANDEIRA, 2018). As questôes ligadas ao uso e comercialização de drogas são um dos principais motivos de encarceramento no Brasil (MINAYO; DESLANDES, 1998). Não coincidentemente, a maior parte da população carcerária do país é negra e jovem (entre 18 e 29 anos), tendo cursado ensino fundamental incompleto e advinda de camadas sociais menos favorecidas.

A realidade prisional brasileira é permeada por relatos de maus-tratos, déficit de vagas e superlotação, estrutura física inadequada, falta de higiene, grande deficiência na assistência à saúde, discriminação, relaçôes de poder, ociosidade e dificuldade de acesso ao trabalho e à educação, além de intensa cultura de violência institucional, marcada por revistas gerais nas celas, transferências repentinas, suspensão de visitas e visitas íntimas, dentre outras medidas administrativas (DIUANA et al., 2008).

A experiência do aprisionamento é um processo complexo e pode causar uma série de reações e sofrimentos, colocando, em última instância, em risco a saúde daquele que se encontra ali encarcerado. Em todo o mundo, já existem pesquisas que demonstram que a prevalência de transtornos mentais é superior na população prisional, quando comparada à populaçáo em geral, sugerindo que esse público necessita de cuidados específicos no que diz respeito à saúde mental (CANAZARO; ARGIMON, 2010). A pesquisa realizada por Coelho (2012) identificou que 12,4\% dos entrevistados de uma unidade prisional brasileira apresentavam sintomas compatíveis com transtornos psicológicos menores, com maiores prevalências para tristeza, ansiedade e insônia, respectivamente. Caldas (2009) apontou que episódios de autolesão são maiores em pessoas em restrição de liberdade do que na população em geral. 
Souza (2004) sinaliza para alguns consensos a partir de uma pesquisa de revisão de literatura que abarcou o sistema prisional de diversos países do mundo:

1 - na maior parte dos presídios, foram identificadas pessoas com transtornos mentais, de modo que esses transtornos são mais prevalentes na população privada de liberdade do que na população em geral;

2 - na maior parte dos presídios do mundo, com exceção da Alemanha e na Noruega, não há tratamento médico clínico adequado, inclusive de sáude mental;

3 - os transtornos mentais mais prevalentes nos presídios estão relacionados ao uso de substâncias psicoativas.

Estudo realizado por Nurse, Woodcock e Ormsby (2003), na Inglaterra, mostrou que o ambiente da prisão tende a provocar sentimentos de raiva, ansiedade e frustração, havendo relatos de períodos longos de isolamento pelos presos, sendo costumeiramente realizado uso de remédios e outras drogas como forma de lidar com o encarceramento. Além disso, os transtornos mentais foram as doenças mais prevalentes entre as mulheres, chegando a $40,7 \%$ da população carcerária feminina no estado da Paraíba (OLIVEIRA et al., 2013).

No Brasil, um estudo realizado por Freire, Pondé e Mendonça (2012), em duas unidades prisionais da Bahia, sinalizou que o uso abusivo ou a dependência do álcool durante a vida esteve presente no depoimento de $61 \%$ dos entrevistados que se encontravam em regime fechado. $\mathrm{O}$ uso de outras drogas, relacionado a um padrão de dependência, foi prevalente em $14,8 \%$ para maconha, $12 \%$ para cocaína ou crack e $0,9 \%$ para inalantes. Maconha $(6 \%)$, cocaína e crack $(0,6 \%)$ também foram citadas como substâncias de abuso atual. Essa mesma pesquisa apontou um padrão de dependência e abuso atual significativamente superior para custodiados do regime semiaberto, sendo a dependência ou o uso abusivo do álcool positivas em $67,7 \%$ dos entrevistados. A maconha foi citada como causadora de dependência ao longo da vida em $20 \%$ dos casos, seguida da cocaína e crack (11,5\%).

O direito à assistência à saúde no sistema penitenciário está garantido desde 1984, ou seja, antes mesmo da criação do Sistema Único de Saúde (SUS), a partir da Lei de Execução Penal (LEP), ${ }^{1}$ que dispóe, em seu art. 14, sobre a atenção à saúde do preso ou internado em caráter preventivo e curativo, definindo atendimento médico, farmacêutico e odontológico. Ressalta ainda que, quando o estabelecimento penal não estiver aparelhado para garantir tal assistência, a mesma deverá ser prestada 
em outro local, mediante autorização da direção da instituição (BRASIL, 1984). Embora se configurando como pioneira na garantia dos direitos das pessoas privadas de liberdade, a LEP parece possuir pouca efetividade, considerando as inúmeras violaçôes aos direitos essenciais que essa população vem sofrendo, tendo limitado o acesso à saúde, à educação, ao trabalho etc.

Buscando uma solução para esse problema, em 2003 foi instituído o Plano Nacional de Saúde no Sistema Penitenciário (PNSSP), por meio da Portaria Interministerial $\mathrm{n}^{\circ}$ 1.777, de 9 de setembro de 2003. ${ }^{2}$ Esse plano obedeceu aos princípios do SUS, buscando "a atenção integral à saúde da população prisional confinada em unidades masculinas, femininas, bem como nas psiquiátricas” (BRASIL, 2003, p. 1). Esse plano se configurou como um avanço na legislaçáo brasileira, pois foi a primeira vez que a população prisional foi alvo de uma política de saúde específica. Vale ressaltar que a sua execução prevê o financiamento para a organização da estrutura física e pagamento de recursos humanos, que inclui médico, assistente social, psicólogo, odontólogo, assistente de consultório odontológico, enfermeiro e técnico de enfermagem. Em seu Art. 5, essa portaria define como alvo de atuação:

Ações de promoção da saúde e de atenção no nível básico relativas à saúde bucal, saúde da mulher, doenças sexualmente transmissíveis/Aids, saúde mental, hepatites, tuberculose, hipertensão, diabetes, hanseníase, bem como a assistência farmacêutica, básica, imunizaçóes e coleta de exames laboratoriais (BRASIL, 2003, p. 2).

No que diz respeito à saúde mental, as açóes de Redução de Danos (RD) estavam previstas na supracitada portaria, estabelecendo, dentre outros, a distribuição de insumos para a Redução de Danos e a realização de atendimentos em situaçôes de prejuízos à saúde decorrentes do uso de álcool e outras drogas em 100\% das unidades prisionais (BRASIL, 2003).

Essa portaria foi substituída em 2014 pela Portaria Interministerial $n^{\circ} 1$, que instituiu a Política Nacional de Atenção Integral à Saúde das Pessoas Privadas de Liberdade no Sistema Prisional (PNAISP). Seu objetivo é a garantia do acesso integral da população privada de liberdade ao SUS, por meio da qualificação e humanização da atenção à saúde no sistema prisional, estando prevista uma serie de açôes conjuntas entre a Saúde e a Justiça, nas três esferas do governo (BRASIL, 2014). A PNAISP apresenta como proposta a ampliação da garantia dos direitos sociais e representa um avanço significativo nas políticas de atenção à saúde da pessoa encarcerada. 
Objetiva-se discutir o cuidado ao usuário de drogas dentro do sistema penitenciário, buscando responder aos seguintes questionamentos: quais são os modelos de cuidado ofertados às pessoas que se encontram em privação de liberdade e que fazem uso de substâncias psicoativas (SPAs)? Quais as estratégias que as pessoas custodiadas utilizam para lidar com os efeitos subjetivos do encarceramento? Quais as estratégias usadas para lidar com a suposta "redução da oferta de drogas" dentro das unidades prisionais? Como o uso de psicofármacos é compreendido nesse contexto? Quais mudanças foram identificadas no que diz respeito à assistência à saúde mental da pessoa privada de liberdade após a publicação do PNSSP e do PNAISP? A elucidação de tais interrogaçóes possibilitará uma maior compreensão da realidade prisional no que diz respeito ao consumo de drogas e às políticas de atenção aos usuários de SPAs já implementadas.

\section{Metodologia}

Trata-se de um estudo exploratório-descritivo, considerando que o objeto em questão é pouco estudado. Foi definida como procedimento metodológico a pesquisa bibliográfica, a qual se configura como uma forma de sintetizar as informações disponíveis sobre um problema específico, em determinado espaço de tempo (LIMA; MIOTO 2007). Foi construído um protocolo de pesquisa, sendo as etapas da investigação, bem como as perguntas da mesma, as estratégias de busca dos artigos dentro do universo de pesquisa, os critérios de inclusão e exclusão e as etapas para a análise e síntese dos dados, conforme modelo sugerido por Lima e Mioto (2007):

1. Elaboração do projeto de pesquisa: formulação do problema da pesquisa e construção de um plano que objetivou responder às questôes formuladas.

2. Investigação das soluçóes: coleta da documentação, englobando: a) levantamento da bibliografia; b) levantamento das informaçôes contidas na bibliografia.

Para o levantamento bibliográfico, foram definidos alguns parâmetros:

Parâmetro temático: obras relacionadas ao tema do uso de drogas no sistema prisional, tendo como critérios de exclusão aqueles trabalhos que abordassem exclusivamente questôes relacionadas à saúde do trabalhador, a questão do uso de drogas na adolescência/menor infrator, o comércio/tráfico de drogas, as pessoas 
privadas de liberdade que se encontram reclusas em unidades psiquiátricas, além de artigos quantitativos, de revisão da literatura ou de relato de experiência.

Parâmetro linguístico: obras no idioma português, inglês ou espanhol, desde que o Brasil se configurasse como país no qual a pesquisa foi realizada.

Parâmetro cronológico: foi definido que seriam incluídos os artigos e textos publicados entre 2003 (lançamento do Plano Nacional de Saúde no Sistema Penitenciário) e 2015.

Outro critério de inclusão definido foi a disponibilidade do texto completo nas bases de dados virtuais, sendo utilizada para pesquisa a Biblioteca Virtual em Saúde (BVS). As buscas eletrônicas foram realizadas em setembro de 2015.

Foram utilizados os seguintes descritores listados na tabela 1, sendo encontrados 129 artigos. Excluindo os artigos repetidos, permaneceram 50.

Tabela 1. Lista de descritores utilizados para a pesquisa na Biblioteca Virtual em Saúde. Bahia, 2015

\begin{tabular}{|l|l|}
\hline Descritor & N \\
\hline Abstinência & 3 \\
\hline Álcool & 5 \\
\hline Ansiolítico & 0 \\
\hline Antidepressivos & 0 \\
\hline Antipsicótico & 0 \\
\hline Centros de Atenção Psicossocial & 1 \\
\hline Cocaína & 3 \\
\hline Crack & 1 \\
\hline Doença Mental & 11 \\
\hline Drogas & 18 \\
\hline Drogas Injetáveis & 3 \\
\hline Fármacos & 3 \\
\hline Maconha & 1 \\
\hline Psicofármacos & 0 \\
\hline Psicopatologia & 0 \\
\hline
\end{tabular}

continua... 


\begin{tabular}{|l|l|}
\hline Descritor & N \\
\hline Psicossocial & 1 \\
\hline Reduçáo De Danos & 2 \\
\hline Remédio & 1 \\
\hline Resistência & 6 \\
\hline Saúde & 42 \\
\hline Saúde Mental & 13 \\
\hline Substâncias Psicoativas & 6 \\
\hline Tabaco & 0 \\
\hline Tabagismo & 3 \\
\hline Transtornos Relacionados ao Uso de SPAs & 6 \\
\hline TOTAL & 129 \\
\hline
\end{tabular}

Fonte: elaboração própria.

Durante a pesquisa na Biblioteca Virtual em Saúde, foram localizados artigos publicados principalmente na Lilacs (33) e na Medline (12), sendo que um artigo foi publicado no Portal HISA (História da Saúde), três no BDENF (Base de Dados de Enfermagem) e um no Index-Psicologia, a partir dos descritores já referidos. Após a aplicação dos testes de relevância listados abaixo, foram selecionados 20 artigos, sendo 14 disponibilizados na LILACS, quatro na Medline, um na Index-Psicologia, um na BDENF.

Conforme apresentado na tabela 2, do ponto de vista cronológico, a maior parte dos artigos (13) foi publicada em 2014, ano da publicação da PNAISP. Nenhum artigo foi publicado em 2003, ano de lançamento do PNSSP:

Tabela 2. Frequência anual de trabalhos publicados na Biblioteca Virtual em Saúde. Bahia, 2015

\begin{tabular}{|c|c|c|c|c|c|c|c|c|c|c|c|c|c|c|}
\hline Ano & 2003 & 2004 & 2005 & 2006 & 2007 & 2008 & 2009 & 2010 & 2011 & 2012 & 2013 & 2014 & 2015 & Total \\
\hline $\mathrm{N}$ & 0 & 3 & 1 & 3 & 4 & 0 & 3 & 2 & 6 & 6 & 6 & 13 & 3 & 50 \\
\hline
\end{tabular}

Fonte: elaboração própria. 
O levantamento das informações contidas na bibliografia obedeceu a duas etapas distintas:

Teste de relevância I: objetivou o refinamento da seleção original de artigos, sendo efetuada a leitura dos resumos dos 50 estudos. Essa leitura prévia buscou identificar aqueles trabalhos que obedeciam aos critérios de inclusão, relacionando, portanto, o uso de drogas ao sistema penitenciário. Foram removidas as referências que notoriamente não cumpriam o critério de inclusão, restando 20 trabalhos, que foram lidos integralmente. Como método complementar de busca bibliográfica, foi realizada uma pesquisa no referencial teórico desses 20 trabalhos previamente selecionados, sendo identificados mais 26 textos, entre artigos e capítulos de livros. Essa primeira etapa foi reaplicada nessas 26 obras, sendo selecionados outros 06 estudos para leitura integral.

No que diz respeito à pesquisa bibliográfica complementar, conforme apresentado na tabela 3, dos 26 artigos e textos identificados, três eram capítulos de livros, publicados pela Editora da UFBA (EDUFBA), sendo um publicado em 2013, e os outros dois em 2012. Os 23 artigos restantes encontrados obedeceram à seguinte cronologia de publicação:

Tabela 3. Frequência anual de trabalhos publicados - metodologia complementar de busca de materiais. Bahia, 2015

\begin{tabular}{|c|c|c|c|c|c|c|c|c|c|c|c|c|c|c|}
\hline Ano & 2003 & 2004 & 2005 & 2006 & 2007 & 2008 & 2009 & 2010 & 2011 & 2012 & 2013 & 2014 & 2015 & Total \\
\hline $\mathrm{N}$ & 2 & 1 & 0 & 5 & 1 & 1 & 1 & 3 & 2 & 2 & 3 & 1 & 1 & 23 \\
\hline
\end{tabular}

Fonte: elaboração própria.

Teste de relevância II: os 26 trabalhos (20 provenientes de bases de dados virtuais e seis de pesquisa bibliográfica complementar) que passaram para essa etapa necessariamente responderam a algumas premissas básicas, além dos critérios já definidos: se a metodologia estava suficientemente clara e adequada aos objetivos, e se os resultados estavam compatíveis com a metodologia empregada.

Dos 26 artigos selecionados, seis cumpriram os critérios presentes no segundo teste de relevância, estando listados na tabela 4, apresentada abaixo, de acordo com a ordem de publicação. Os dados obtidos a partir desses seis trabalhos foram analisados por meio da análise de conteúdo, objetivando, por meio de procedimentos sistemáticos, identificar indicadores qualitativos que possibilitam construir conhecimentos: 
Tabela 4. Lista de artigos utilizados para a síntese de dados bibliográficos. Bahia, 2015

\begin{tabular}{|c|c|c|c|c|}
\hline $\mathrm{N}$ & Título & Autor(es) & Ano & Estado \\
\hline 1 & $\begin{array}{l}\text { Subjetividade e estratégias de } \\
\text { resistência na prisão }\end{array}$ & $\begin{array}{c}\text { Cristian Fabiano Guimaraes, Stela } \\
\text { Nazareth Meneghel, Carmen } \\
\text { Silveira de Oliveira }\end{array}$ & 2006 & RS \\
\hline 2 & $\begin{array}{l}\text { Intervençóes Psicossociais no } \\
\text { Sistema Carcerário Feminino }\end{array}$ & Marcela Ataide Guedes & 2006 & MG \\
\hline 3 & $\begin{array}{c}\text { Avaliaçáo das Ações de Redução } \\
\text { de Danos no Sistema Prisional } \\
\text { Brasileiro }\end{array}$ & Omar Alejandro Bravo & 2009 & RS \\
\hline 4 & $\begin{array}{l}\text { O cuidado na Atenção primária à } \\
\text { saúde da População carcerária no } \\
\text { município de Carnaúba/RN }\end{array}$ & $\begin{array}{c}\text { João Wellton de Azevedo } \\
\text { Henrique Júnior, Patrícia Angélica } \\
\text { de Oliveira Tavares, Janieiry Lima } \\
\text { de Araújo, Ellany Gurgel Cosme } \\
\text { do Nascimento, João Mário Pessoa } \\
\text { Júnior, João Carlos Alchiere }\end{array}$ & 2013 & $\mathrm{RN}$ \\
\hline 5 & $\begin{array}{l}\text { O contraditório direito à saúde de } \\
\text { pessoas em privação de liberdade }\end{array}$ & $\begin{array}{l}\text { Élida Lúcia Carvalho Martins, } \\
\text { Luciana Gomes Martins, Andréa } \\
\text { Maria Silveira, Elza Machado de } \\
\text { Melo. }\end{array}$ & 2014 & MG \\
\hline 6 & $\begin{array}{l}\text { Drogadiçáo no cárcere: questóes } \\
\text { acerca de um projeto de } \\
\text { desintoxicação de drogas para } \\
\text { pessoas privadas de liberdade }\end{array}$ & $\begin{array}{c}\text { Helena Salgueiro Lermen, Tamires } \\
\text { Dartora, Carine Capra-Ramos }\end{array}$ & 2014 & RS \\
\hline
\end{tabular}

Fonte: elaboração própria.

\section{Resultados e Discussão}

Os artigos encontrados a partir dessa pesquisa apontam para graves problemas no que diz respeito às condiçôes de saúde no sistema prisional, sendo o encarceramento compreendido como nocivo à saúde global dos sujeitos.

\section{Efeitos subjetivos e estratégias para lidar com o encarceramento}

Do ponto de vista dos efeitos subjetivos do encarceramento, a preocupação e a saudade da família são elementos fortemente relatados como ansiogênicos, sendo 
identificado que o envolvimento de muitas mulheres encarceradas em relaçôes homoafetivas tem a finalidade não apenas de obter proteção e cuidado, mas serve também como uma forma de preservar o afeto (GUEDES, 2006). Além disso, Guedes (2006) identificou que a ociosidade no encarceramento é vista como um elemento desgastante; apesar disso, apenas um pequeno percentual das mulheres encarceradas frequenta a escola ou exerce atividade laboral na prisão (OLIVEIRA et al., 2013). Outros elementos estressores para o convívio na coletividade forçado pela prisão são a falta de liberdade para fazer o que se deseja, no momento em que se deseja, e a dificuldade em ficar só. Paradoxalmente, a prisão também é vista como uma proteção diante das incertezas do futuro ou da vida, especialmente para aqueles que tinham envolvimento com o crime organizado, sendo que, em alguns casos, o medo de ser solto equivale ao medo de ser preso (GUEDES, 2006).

Diante dosinúmeros elementos que podem levar ao sofrimento no encarceramento, Guimarães, Meneghel e Oliveira (2006) apontam para a existência de duas formas de resistência à prisão, as quais teriam como função não apenas chamar a atenção da sociedade e lutar contra o esquecimento, mas sobretudo objetivariam a diminuição desse sofrimento. A primeira forma de resistência é a "ativa”, a qual, por meio da criatividade, produz uma mudança na posição ocupada pela pessoa privada de liberdade. Essa forma de resistência se constitui como a potência geradora de novas formas de vida, tem o poder da inventividade, se constituindo como forte operador de mudanças. Exemplos seriam as atividades artísticas desempenhadas, além das educacionais, entre outras.

Contudo, as formas de resistências "reativas" acabam por conduzir o sujeito a um modo de produção de subjetividades que é fortemente marcado pelo individualismo e por uma identidade fixada na delinquência, o que também produz o assujeitamento e a vitimização desses sujeitos. Nesses casos, os sujeitos se percebem e atuam como criminosos, barganhando suas necessidades à margem da lei. A identidade de criminoso permite a obtenção de vantagens no convívio social (dentro ou fora da prisão), por meio do medo e da intimidação. Os autores sinalizaram que muitos apenados são identificados e se reconhecem a partir do crime pelo qual foram condenados, estabelecendo, a partir desses, relaçóes hierárquicas dentro do sistema prisional, passando a ser esta a única forma de algum reconhecimento social.

Corroborando esses achados, a pesquisa realizada por Guedes (2006) identificou cinco estratégias principais para lidar com a privação de liberdade. Poderíamos 
chamar essas estratégias de ativas, partindo da perspectiva endossada por Guimarães, Meneghel e Oliveira (2006):
1) Realização de trabalho na limpeza (com a possibilidade de obterem a remição da pena);
2) atividades de artesanato;
3) o cuidado com própria aparência ou com o espaço da cela;
4) apego aos filhos e demais familiares e
5) participação no grupo de alfabetização ou grupos de oração organizados por entidades religiosas diversas (GUEDES, 2006, p. 566).

A experiência da autora no sistema prisional na Bahia apontou para um evento que não foi encontrado na literatura pesquisada, que é a fabricação e consumo de tipos específicos de drogas no interior das prisōes, que poderíamos chamar de "drogas artesanais". Mesmo com muitos investimentos por parte da segurança carcerária, é comum no interior das unidades prisionais baianas a fabricação da chamada "Maria Louca", uma bebida alcoólica artesanal que pode ser fabricada a partir de produtos variados como cascas de frutas ou cereais. Além disso, muitos internos tendem a fumar pequenas plantas encontradas nos pátios das prisões. Tais iniciativas por parte dos internos ratificam os achados da literatura de que, mesmo em uma instituição total, na qual são levantadas inúmeras barreiras para controlar e privar os sujeitos do contato com o mundo exterior (GOFFMAN, 1987), as pessoas privadas de liberdade desenvolvem uma serie de estratégias de contracontrole e para construir a própria realidade.

Quando pensamos na fabricação artesanal da "Maria Louca", precisa-se considerar que não estamos falando apenas de um consumo, mas também de um processo criativo de trabalho, que exige alto nível de organização e performance, especialmente quando considerado o contexto dessa produção. Ora, se levarmos em consideraçáo o acentuado nível de ociosidade ao qual são submetidas as pessoas que estão privadas de liberdade, é minimamente compreensível a realização de tais práticas, que passam não apenas a gerar um produto que pode ser consumido ou negociado dentro da unidade, mas que fornecem àqueles envolvidos (os fabricantes) certo prestígio perante os pares. Como salienta Espinheira (2004), a droga pode assumir então uma função existencial, com implicações diretas, inclusive, na sociabilidade, isso mesmo dentro de uma prisão. Acredita-se que a produção e consumo da "Maria Louca" e outras drogas artesanais pode ser uma estratégia de resistência à vida dentro da prisão, funcionando como um dispositivo promotor de saúde mental. 


\section{Redução de oferta de drogas?}

Segundo Lermen, Dartora e Capra-Ramos (2014), o uso de SPAs se configura como dispositivo que ameniza as tensóes presentes nas prisóes, envolvendo uma situação ambígua: controle do uso versus acordos tácitos estabelecidos dentro das unidades prisionais, que apontam para os benefícios do uso nesse contexto. Citando os autores:

Os apenados contaram que a droga é "o combustível da prisão", e que sem ela, a "prisão explode", confirmando que o consentimento de uso de substâncias psicoativas no interior dos estabelecimentos penais exerce função de contenção. Contudo, essa atividade os coloca em um circuito de criminalização, pois contribui para seu assujeitamento e para o aumento da penalização (GUIMARÁES; MENEGHEL; OLIVEIRA, 2006, p. 640).

A pesquisa de Guimarães et al. (2008) observou que 40\% das pessoas presas relataram uso de algum tipo de droga na prisão, com maior prevalência para uso do tabaco e da maconha. Ferreira Filho et al. (2003) também identificaram que 31\% dos presos paulistas referiram uso de SPAs durante o encarceramento. Corroborando tais achados na literatura, a pesquisa de Quitete et al. (2012) identificou que 53\% das mulheres encarceradas em uma unidade prisional do Rio de Janeiro narraram uso diário de algum tipo de droga ilícita, sendo a maconha a mais consumida (41,7\%), seguida da cocaína (27,6\%). Dados similares foram encontrados por Carvalho et al. (2006), cuja pesquisa indica que o uso de drogas na prisão está relacionado ao uso anterior ao encarceramento, com predomínio para o consumo de bebidas alcoólicas. Essa pesquisa indicou que $33 \%$ dos entrevistados relataram consumo, durante o período de cumprimento da pena, de ao menos uma droga, sendo que a utilizaçáo da maconha foi predominante entre os homens.

Não foram localizados estudos que abordassem especificamente o uso de psicofármacos dentro do sistema prisional. Algumas pesquisas fizeram breve referência ao assunto, como a de Carvalho et al. (2006), que sinalizou que os tranquilizantes foram as drogas mais consumidas pelas mulheres encarceradas, chamando atenção para a utilização de psicofármacos como um meio de lidar com a perda da liberdade e com as consequências físicas e psicológicas do encarceramento. Achado similar foi elucidado no estudo de Quitete et al. (2012), no qual se evidenciou que muitas mulheres encarceradas relataram comprar clandestinamente "calmantes", objetivando suportar o sofrimento psíquico. Junior et al. (2013) apontam para a dispensa de medicamentos controlados como um elemento marcante dentro das prisóes. 
O que nos cabe interrogar é o motivo pelo qual o uso de psicofármacos não se constitui como interesse entre os pesquisadores. Durante o meu período de atuação em uma unidade prisional feminina, mais de $50 \%$ das mulheres faziam uso diário de psicofármacos, estando os ansiolíticos entre as drogas mais prescritas, especialmente em decorrência de queixas frequentes de insônia e ansiedade. A medicalização das pessoas que se encontram privadas de liberdade parece ser interpretada pelos profissionais que atuam no Sistema Prisional como uma assistência à saúde dessas, notadamente à saúde mental, sinalizando para uma compreensão biomédica e curativista acerca da saúde mental e do sofrimento decorrente do encarceramento.

A literatura, de modo geral, já sinaliza como real e significativo o consumo de drogas dentro do sistema prisional (GUIMARÁES et al., 2008; QUITETE et al., 2012), mas, infelizmente, essa realidade não é considerada pelas secretarias que administram as unidades prisionais no Brasil. Contudo, os autores das supracitadas pesquisas ressaltam que tais dados podem estar enviesados, para não dizer subestimados, uma vez que o consumo de drogas ilícitas dentro de uma unidade prisional se constitui como ato infracional grave, podendo o apenado sofrer inúmeras sançôes. Contraditoriamente, a pesquisa de Oliveira et al. (2013) aponta que alguns hábitos comuns no cárcere, tais como o uso de drogas, sejam elas lícitas, ilícitas ou prescritas, também contribuem para o adoecimento das pessoas presas. Isso significa que, apesar do consumo de drogas estar relacionado a uma estratégia para lidar com o encarceramento, esse uso também produz malefícios à saúde geral dos sujeitos, produzindo uma reação cíclica, que merece ser não apenas reconhecida pelo Estado, mas também objeto de políticas de cuidado.

\section{Cuidados oferecidos aos usuários de drogas privados de liberdade}

Apesar de toda a problemática apontada pela literatura, essa pesquisa bibliográfica identificou apenas dois estudos que abordavam diretamente a atenção à saúde dos usuários de drogas que se encontram presos. O primeiro artigo, produzido por Bravo (2009), buscou avaliar açóes de redução de danos desenvolvidas em alguns estabelecimentos penais no Brasil, almejando identificar os sucessos já conseguidos e os entraves institucionais.

Bravo observou como um primeiro entrave a proibição de distribuição de seringas dentro das unidades, por ser o consumo de SPAs considerado prática ilegal. Em alguns presídios, contudo, foi possível apresentar o kit de Redução de Danos aos internos. 
Tal achado aponta para um abismo no que diz respeito ao que está estabelecido na legislação com o que se evidenciou na prática cotidiana dos presídios. Além disso, o mesmo autor notou que a ideologia predominante entre os dirigentes das unidades prisionais estudadas é de caráter fortemente conservador, embora demonstrando certa abertura para a compreensão do que seria a perspectiva da Redução de Danos (BRAVO, 2009). A pesquisa realizada com agentes penitenciários, por sua vez, apontou para um alto grau de resistência, relacionada especialmente ao preconceito acerca dos direitos dos custodiados, associada às queixas quanto à ausência de políticas de saúde dirigidas aos próprios agentes (BRAVO, 2009). Contudo, esse estudo sinalizou para o alto investimento e apoio dos detentos aos projetos de Redução de Danos, apesar de muitos multiplicadores apresentarem discursos conservadores no que diz respeito à distribuição de kits, corroborando a ideologia presente entre os dirigentes das unidades prisionais pesquisadas. Esse achado aponta na mesma direção que os encontrados nas pesquisas anteriores, acerca do movimento de contrapoder e resistência desenvolvido pelas pessoas em privação de liberdade.

Outro estudo identificado na pesquisa bibliográfica foi realizado por Lermen, Dartora e Capra-Ramos (2014), o qual objetivou avaliar um projeto de desintoxicação para usuários de drogas que se encontravam privados de liberdade, calcado na lógica da abstinência total. Esse projeto teve início em 2011, por meio de um convênio entre a Secretaria Estadual de Saúde do Rio Grande do Sul e Hospital Vila Nova, de Porto Alegre. Foram pactuados 18 leitos para desintoxicação de pessoas presas que se disponibilizassem voluntariamente, não se tratando, portanto, de uma ação de internação compulsória.

De acordo com o projeto citado, após ser avaliado como elegível pela equipe que atua na prisão, a pessoa permanece 21 dias internada no hospital, no qual recebe assistência multiprofissional. Durante esse período, deve-se permanecer abstinente a qualquer tipo de drogas, sendo ela lícita ou ilícita (exceto os psicofármacos prescritos). Após a internação, a pessoa retorna ao Presidio Central de Porto Alegre, sendo frequentemente submetida a exames de urina, para comprovar que não houve recaídas, sendo expulsa do projeto caso seja identificado algum consumo. Éimportante salientar que a permanência nesse projeto durante o período de encarceramento proporciona algumas vantagens para a pessoa encarcerada: ela passa a receber uma assistência à saúde diferenciada; permanece em locais sem superlotação; passa a ser vista como "bom preso", como passível de uma ressocialização, o que pode contar 
como favorável durante o procedimento de avaliação criminológica para progressão de regime. Seria, portanto, a decisão de participar desse projeto mais uma estratégia de resistência à prisão? Embora não tenhamos condiçôes de responder diretamente a essa pergunta, é possível observar que há relevantes ganhos em jogo. Além disso, não foram identificados dados referentes à manutenção da abstinência após a saída do sistema prisional.

A literatura aponta que há poucas ofertas de ações de redução de danos dentro do sistema prisional, sendo mais prevalente aquelas pautadas na abstinência, com caráter essencialmente curativista (JUNIOR et al., 2013). Essas açóes centradas na medicina curativista sinalizam para a resistência em considerar a saúde como um direito da pessoa privada de liberdade, uma vez que se deixa de realizar açôes que visem à promoção de saúde e à prevenção de agravos.

Outro elemento que chama atenção na referida pesquisa é o consenso identificado entre os próprios profissionais que atuam no sistema prisional acerca da precariedade do cuidado e da necessidade de avanços significativos na assistência (JUNIOR et al., 2013). A pesquisa realizada por Martins et al. (2014) apresenta uma perspectiva consensual em relação à já citada, ao sinalizar que o direito à saúde é identificado pelas pessoas privadas de liberdade como algo que não se concretiza na prática cotidiana, sendo essa percepção partilhada por profissionais de saúde das unidades prisionais, bem como por agentes penitenciários. Para os entrevistados dessa pesquisa, que incluíram pessoas custodiadas, profissionais de saúde e agentes penitenciários, o descaso com o direito à saúde está relacionado à função da prisão, a qual é fortemente associada à segurança e disciplina.

Oliveira et al. (2013) sinalizaram ainda que, no presídio feminino estudado, o número de mulheres encarceradas que recebem acompanhamento à saúde é inferior ao número daquelas que receberam algum diagnóstico. Isso indica que a população carcerária esbarra em uma serie de barreiras no acesso à saúde, seja na rede pública de serviço, ou mesmo nos serviços que são ofertados dentro do próprio estabelecimento penal. Infelizmente, muitas vezes as pessoas encarceradas precisam fazer uso de algumas estratégias para ter acesso aos serviços de saúde: "se você tem bom relacionamento com os agentes, é mais fácil que seu direito seja respeitado" (MARTINS et al., 2014, p. 1229).

Contudo, nota-se uma ambivalência entre os profissionais das unidades prisionais no que diz respeito ao direito à saúde: se por um lado há uma crítica em relação à 
não efetivação desse direito; por outro, há uma recusa a atribuir ou legitimar esse direito da pessoa privada de liberdade. Um exemplo disso são as constantes críticas dos agentes penitenciários acerca da ausência de assistência voltada para a saúde do trabalhador. Durante minha atuação no sistema prisional, eram corriqueiras falas como "para os presos tudo; para nós, nada". Cabe interrogar sobre quais sentimentos são despertados nos profissionais que atuam no sistema penitenciário, especialmente diante do sensacionalismo que envolve a questão da violência urbana, criminalidade, e do clamor por uma justiça maniqueísta, que desconsidera toda a desigualdade social, que em muito contribui para a violência e criminalidade. Para Junior et al. (2013), existem barreiras no cuidado ofertado às pessoas privadas de liberdade, que são o medo gerado pelo estigma de ser presidiário, portanto uma pessoa criminosa, de caráter minimamente duvidoso, além de outras questôes relacionadas à qualificação profissional e ao preconceito propriamente dito.

Outros achados a partir da pesquisa bibliográfica apontam para um elemento ainda mais delicado no que diz respeito à assistência à saúde das pessoas privadas de liberdade. Segundo Junior et al. (2013), a maior parte dos profissionais que atuavam no Sistema Prisional não conhecia bem o PNSSP, lançado em 2003. Segundo os autores, dez anos após a publicação da portaria, os profissionais da gestão foram os que mais demonstraram conhecer o referido plano, sendo notório o desconhecimento dos demais profissionais sobre os eixos de ação do PNSSP. Curiosamente, a pesquisa de Bravo (2009) identificou que os médicos eram a categoria profissional que apresentava maior resistência às açôes de $\mathrm{RD}$, ao passo que psicólogos e enfermeiros demonstraram ser os mais engajados. Somado a isso há a baixa qualificação dos profissionais que atuam em unidades prisionais e uma não sistematização de propostas para o cuidado com essa população, tanto no período de encarceramento, quanto após a reconquista da liberdade ${ }^{3}$.

A utilização de estratégias de RD em pessoas privadas de liberdade é absolutamente necessária, considerando a intensa vulnerabilidade dessa população, e a dificuldade de acesso a outras formas de prevenção e cuidado (BRAVO, 2009). Se as açôes de RD estão legalmente garantidas para o sistema prisional, na prática essa realidade mostrase bastante complexa. Vamos analisá-la a partir de três características apontadas por Andrade (2004) como pertencentes à perspectiva de RD. A “pragmática” diz respeito à clareza dos objetivos da $\mathrm{RD}$, que seria, dentre outros, a prevenção de doenças e a defesa da vida, independentemente da manutençáo do consumo de 
SPAs. A "tolerância”, por sua vez, se refere ao necessário respeito que se deve ter com os usuários e ao direito desses às suas drogas de consumo.

A reflexão sobre esses dois princípios nos leva a concluir que a prática de RD se torna impossível dentro do espaço carcerário. Inicialmente, temos a proibição absoluta do consumo de qualquer tipo de droga dentro das unidades prisionais, em alguns casos essa proibição se estende inclusive ao tabaco. Contudo, percebe-se um movimento das pessoas que estáo privadas de liberdade na direçâo do rompimento com esse proibicionismo, à medida que se sabe que o consumo de drogas é comum dentro dessas unidades. Esse dado, embora não seja assumido de forma madura e coerente pelo Estado, já é apontado por diversos estudos (CARVALHO et al., 2006; QUITETE et al., 2012; FERREIRA FILHO et al., 2003).

Pode-se considerar que o primeiro grande entrave para as intervenções de RD dentro do sistema prisional localiza-se, portanto, em uma esfera de Estado/gestão, uma vez que este sequer admite que ocorra uso de drogas dentro das unidades prisionais. Não admitir esse uso implica tornar invisível grosseiramente o problema, o qual tende a se agravar progressivamente:

O consumo de drogas é demasiadamente alto nas unidades prisionais. Porém, o Estado não reconhece oficialmente a existência de drogas em locais de detenção, pois se o faz, admite que seus próprios agentes participam do acesso e distribuição da droga ou, no mínimo, convivem pacificamente com a presença ilegal da droga no interior das unidades prisionais. Como consequência, as autoridades responsáveis deixam de agir preventivamente pelo controle do consumo de drogas. No Estado do Rio de Janeiro, estudo oficial indica que para cada ano de permanência na prisão, aumenta em 13\% a chance de uso de cocaína (BRASIL, 2007, p. 35-36).

A terceira característica apontada por Andrade (2004) é o respeito à "diversidade". Trata-se da inclusão de diferentes práticas de RD, diante de uma multiplicidade não apenas de populaçóes de usuários, mas também de tipos de drogas e formas de consumi-las. Isso significa dizer que as açóes de RD dentro do sistema prisional precisariam levar em consideração as características dessa população, que normalmente se encontra em situação de grande vulnerabilidade, assim como a forma de consumo dentro dessas unidades, a qual é marcada pelo proibicionismo e pela violência.

Mesmo com uma série de dispositivos que regulamentam a prática de $\mathrm{RD}$, inclusive dentro do sistema prisional, há muita resistência por parte do Estado a apoiar açôes nas quais profissionais de saúde abordem certos temas, como a proposta 
de substituição de algumas drogas por outras de menor potencial agressivo, ou ainda o uso mais consciente e saudável de SPAs. Há uma compreensão equivocada de que abordar a temática da Redução de Riscos e Danos poderá incentivar o consumo de drogas ilícitas, e o consequente tráfico das mesmas.

\section{Considerações finais}

Embora a LEP, assim como o PNSSP e a PNAISP, seja considerada marco para o processo de implantação dos direitos sociais da população que se encontra privada de liberdade, o que se observa é que o direito à assistência à saúde está muito longe de ser efetivado dentro das unidades prisionais. Infelizmente, o que se identifica a partir das pesquisas realizadas é que normalmente os internos não recebem assistência médica adequada, o que se reflete em um verdadeiro descaso com a saúde física e emocional das pessoas que se encontram encarceradas, culminando não apenas na privação de liberdade, mas também de dignidade.

A verbalização dos presos que se encontram em sofrimento psíquico parece não se constituir como prova suficiente para demonstrar a necessidade de assistência à saúde, muito menos à saúde mental. Diante disso, só resta às pessoas que se encontram presas construir estratégias ativas ou reativas para lidar com o sofrimento decorrente ou acentuado pelo encarceramento. O consumo de drogas lícitas, ilícitas ou prescritas, sendo elas provenientes de fabricação dentro da própria unidade ou adquiridas por meios ilegais, está no contexto dessas estratégias de resistência, embora esse uso de drogas ilícitas não seja admitido pelo Estado, e a utilização de psicofármacos se apresente mascarada como uma estratégia de cuidado. Essa realidade evidenciada a partir da pesquisa bibliográfica destrói o mito de que no ambiente carcerário a possibilidade de consumir drogas estaria reduzida.

Apesar do consumo de SPAs ocorrer durante o encarceramento, os dados levantados a partir da literatura indicam que as açôes de Redução de Danos são poucas e frágeis dentro do sistema prisional. Isso ocorre inclusive por serem as prisôes espaços nos quais o uso de SPAs não é tolerado nem admitido, tornando as açôes de RD impertinentes. À medida que não se admite o consumo de drogas dentro das prisôes, passa-se a ratificar uma lógica proibicionista, calcada na abstinência, desconsiderando tanto o PNSSP como a PNAISP, sendo que este primeiro faz menção explícita à estratégia de Redução de Danos. 


\section{Referências}

ANDRADE, T. M. Redução de danos: um novo paradigma? In: ALMEIDA, A. R. de et al. (Orgs.). Drogas: tempos, lugares e olhares sobre seu consumo. Salvador: EDUFBA; CETAD/ UFBA, 2004. p. 87-95.

BRASIL. Centro pela Justiça e pelo Direito Internacional. Relatório sobre Mulheres Encarceradas no Brasil. Brasília: Ministério da Justiça, 2007.

. Lei n. ${ }^{\circ}$ 7.210, de 11 de julho de 1984. Institui a Lei de Execução Penal. Diário Oficial da União, Poder Executivo, Brasília, DF, 13 jul. 1984.

- Ministério da Saúde. Ministério da Justiça. Portaria Interministerial no 1777, de 9 de setembro de 2003. Aprova o Plano Nacional de Saúde no Sistema Penitenciário, constante do Anexo 1, destinado a prover a atenção integral a saúde da população prisional confinada em unidades masculinas e femininas, bem como nas psiquiátricas. Diário Oficial da União da República Federativa do Brasil. Brasília, DF, 11 ago. 2003, Seção 1, p. 39-43.

- Ministério da Saúde. Ministério da Justiça. Portaria Interministerial n. 1, de 2 de janeiro de 2014. Institui a Política Nacional de Atenção Integral à Saúde das Pessoas Privadas de Liberdade no Sistema Prisional (PNAISP) no âmbito do Sistema Único de Saúde (SUS). Diário Oficial da República Federativa do Brasil, Brasília, DF, n. 2, 3 jan 2014b. Seção 1, p. 18.

BRAVO, O. A. Avaliação de açôes de redução de danos no Sistema Penitenciário Brasileiro. Psicol. Am. Lat. México, n. 18, nov 2009. Disponível em <http://pepsic.bvsalud.org/scielo.php?script=sci_ arttext\&pid=S1870-350X2009000200002\&lng=pt\&nrm=iso>. Acesso em: 21 ago. 2019.

CALDAS, M. T. et al. Condutas autolesivas entre detentas da Colônia Penal Feminina do Recife. Psicol. estud., Maringá, v. 14, n. 3, p. 575-582, set. 2009 . Disponível em: <http://www. scielo.br/scielo.php?script=sci_arttext\&pid=S1413- 73722009000300019\&lng=pt\&nrm=iso>. Acesso em: 31 ago. 2014. http://dx.doi.org/10.1590/S1413-73722009000300019.

CANAZARO, D.; ARGIMON, I. I. de L. Características, sintomas depressivos e fatores associados em mulheres encarceradas no Estado do Rio Grande do Sul, Brasil. Cad. Saúde Pública. Rio de Janeiro, v. 26, n. 7, p. 1323-1333, jul. 2010 . Disponível em: <http://www. scielo.br/scielo.php?script=sci_arttext\&pid=S0102- 311X2010000700011\&lng=en\&nrm=iso>. Acesso em: 22 jan. 2016. http://dx.doi.org/10.1590/S0102-311X2010000700011.

CARVAlHO, M. L. de et al. Perfil dos internos no sistema prisional do Rio de Janeiro: especificidades de gênero no processo de exclusão social. Ciênc. Saúde Coletiva. Rio de Janeiro ,v. 11,n. 2,p. 461-471, jun. 2006. Disponível em: <http://www.scielo.br/scielo.php?script=sci_ arttext\&pid=S1413-81232006000200023\&lng=en\&nrm=iso >. Acesso em: 1 mar. 2016. http://dx.doi.org/10.1590/S1413-81232006000200023 
COELHO, M. T. A. D. A saúde mental de infratores presos numa unidade prisional da cidade do Salvador. In: COELHO, M. T. A. D.; CARVAlHO FILHO, M. J. (Orgs.). Prisóes numa abordagem disciplinar. Salvador: EDUFBA, 2012. p. 131-144.

COELHO, M. T. A. D.; MASCARENHAS, L. M. O direito à saúde nas prisóes e hospitais de custódia e tratamento do Brasil: em foco a saúde mental. In: LOURENÇO, L. C.; GOMES, G. L. (Orgs.). Prisóes e puniçôes no Brasil contemporâneo. Salvador: EDUFBA, 2013. p. 301-320. DIUANA, V. et al. Saúde em prisóes: representaçóes e práticas dos agentes de segurança penitenciária no Rio de Janeiro, Brasil. Cad. Saúde Pública. Rio de Janeiro, v. 24, n. 8, p. 1887-1896, ago. 2008. Disponível em: <http://www.scielo.br/scielo.php?script=sci_ arttext\&pid=S0102-311X2008000800017\&lng=en\&nrm=iso >. Acesso em: 6 fev. 2016. http:// dx.doi.org/10.1590/S0102-311X2008000800017.

ESPINHEIRA, G. Os tempos e os espaços das drogas. In: ALMEIDA, A. R. de et al. (Orgs.). Drogas: tempos, lugares e olhares sobre seu consumo. Salvador: EDUFBA; CETAD/UFBA, 2004. p. 11-26.

FERREIRA FILHO, O. F. et al. Perfil sociodemográfico e de padróes de uso entre dependentes de cocaína hospitalizados. Rev. Saúde Pública. São Paulo, v. 37, n. 6,p. 751-759, dez. 2003. Disponível em: <http://www.scielo.br/scielo.php?script=sci_arttext\&pid=S003489102003000600010\&lng=en\&nrm=iso>. Acesso em: 22 jan. 2016. http://dx.doi.org/10.1590/ S0034-89102003000600010.

FREIRE, A. C. C.; PONDÉ, M. P.; MENDONÇA, M. S. C. Saúde mental entre presidiários na cidade de Salvador, Bahia, Brasil. In: COELHO, M. T. A. D.; CARVALHO FILHO, M. J. (Orgs.). Prisóes numa abordagem disciplinar. Salvador: EDUFBA, 2012. p. 121-130.

GOFFMAN, E. Manicômios, prisóes e conventos. São Paulo: Perspectiva, 1987.

GOIS, S. M. et al. Para além das grades e puniçôes: uma revisão sistemática sobre a saúde penitenciária. Ciênc. Saúde Coletiva. Rio de Janeiro, v. 17, n. 5, p. 1235-1246, maio 2012. Disponível em: <http://www.scielo.br/scielo.php?script=sci_arttext\&pid=S1413-81232012000500017\&lng= en\&nrm=iso>. Acesso em: 23 jan. 2016. http://dx.doi.org/10.1590/S1413-81232012000500017.

GUEDES, M. A. Intervençóes psicossociais no sistema carcerário feminino. Psicol. Cienc. Prof. Brasília, v. 26, n. 4, p. 558-569, dez. 2006. Disponível em: <http://pepsic.bvsalud.org/ scielo.php?script=sci_arttext $\&$ pid $=\$ 1414-98932006000400004 \& \operatorname{lng}=$ pt $\& n r m=i s o>$. Acesso em: 31 jan. 2016.

GUIMARÁES, C. F. et al. Perfil do usuário de crack e fatores relacionados à criminalidade em unidade de internação para desintoxicação no Hospital Psiquiátrico São Pedro de Porto Alegre (RS). Rev. psiquiatr. Rio Gd. Sul. Porto Alegre , v. 30,n. 2, p. 101-108, ago. 2008. Disponível em: <http://www.scielo.br/scielo.php?script=sci_arttext\&pid=S0101-81082008000300005\&lng=e n\&nrm=iso >. Acesso em: 22 jan. 2016. http://dx.doi.org/10.1590/S0101- 81082008000300005. 
GUIMARÃES, C. F.; MENEGHEL, S. N.; OLIVEIRA, C.S. de. Subjetividade e estratégias de resistência na prisão. Psicol. cienc. prof. Brasília, v. 26,n. 4, p. 632-645, dez. 2006. Disponível em $<$ http://www.scielo.br/scielo.php?script=sci_arttext\&pid=S1414-98932006000400010\&lng=pt \&nrm=iso>. Acesso em: 31 ago. 2014. http://dx.doi.org/10.1590/S1414-98932006000400010.

JUNIOR, J. W. A. H. et.al. O cuidado na atenção primária à saúde da população carcerária no município de Carnaúba-RN. Revista Baiana de Saúde Pública. Salvador, v. 37, n. 2, p. 394-406 abr.-jun. 2013. Disponível em <http://rbsp.sesab.ba.gov.br/index.php/rbsp/article/ view/1228/778>. Acesso em: 21 ago.2019.

LERMEN, H. S. et al. Saúde no cárcere: análise das políticas sociais de saúde voltadas à população prisional brasileira. Physis. Rio de Janeiro, v. 25, n. 3, p. 905-924, set. 2015. Disponível em: <http://www.scielo.br/scielo.php?script=sci_arttext\&pid=S0103-73312015000300905\&lng=p t\&nrm=iso>. Acesso em: 6 fev. 2016. http://dx.doi.org/10.1590/S0103-73312015000300012.

LERMEN, H. S.; DARTORA, T.; CAPRA-RAMOS, C. Drogadição no cárcere: questóes acerca de um projeto de drogas para pessoas privadas de liberdade. Rev. Estudos e Pesquisas em Psicologia. Rio de Janeiro, v. 14, n. 2, p. 539-559, 2014. Disponível em: <http://www. epublicacoes.uerj.br/index.php/revispsi/article/view/12558/9742>. Acesso em: 31 jan. 2016.

LIMA, T. C. S. de; MIOTO, R. C. T. Procedimentos metodológicos na construção do conhecimento científico: a pesquisa bibliográfica. Rev. Katálysis. Florianópolis, v. 10, n. esp., p. 37-45, 2007. Disponível em <http://www.scielo.br/scielo.php?script=sci_arttext\&pid=S141449802007000300004\&lng=pt\&nrm=iso >. Acesso em: 23 jan. 2016. http://dx.doi.org/10.1590/ S1414-49802007000300004.

MARTINS, E. L. C. et al. O contraditório direito à saúde de pessoas em privação de liberdade: o caso de uma unidade prisional de Minas Gerais. Saude Soc. São Paulo, v. 23, n. 4, p. 1222-1234, dez. 2014. Disponível em: <http://www.scielo.br/scielo.php?script=sci_arttext\&pid=S010412902014000401222\&lng=en\&nrm=iso>. Acesso em: 2 fev. 2016. http://dx.doi.org/10.1590/ S0104-12902014000400009.

MINAYO, M. C. de S.; DESLANDES, S. F. A complexidade das relaçóes entre drogas, álcool e violência. Cad. Saúde Pública. Rio de Janeiro, v. 14, n. 1, jan. 1998. Disponível em: <http:// www.scielo.br/scielo.php?script=sci_arttext $\&$ pid=S0102-311X1998000100011\&lng=en \&nrm= iso>. Accesso em: 31 ago. 2014. http://dx.doi.org/10.1590/S0102-311X1998000100011.

NASCIMENTO, L. G. do; BANDEIRA, M. M. B. Saúde penitenciária, promoção de saúde e redução de danos do encarceramento: desafios para a prática do psicólogo no sistema prisional. Psicol. cienc. prof. Brasília, v. 38, n. esp. 2, p. 102-116, 2018. Disponível em <http://www.scielo. br/scielo.php?script $=$ sci_arttext\&pid=S1414-98932018000600102\&lng=pt\&nrm=iso $>$. Acesso em: 16 mar. 2019. http://dx.doi.org/10.1590/1982-3703000212064. 
NURSE, J.; WOODCOCK, P.; ORMSBY, J. Influence of environmental factors on mental health within prisons: focus group study. BMJ, n. 327, p. 480-483, 2003.

OLIVEIRA, L. V. et al. Epidemiological profile of female detainees in the Brazilian state of Paraiba: a descriptive study. Online Braz J Nurs., v. 12, n. 4, p. 892-901, dez. 2013. Disponível em: http:// www.objnursing.uff.br/index.php/nursing/article/view/4284. http://dx.doi. org/10.5935/1676- 4285.20134284

QUITETE, B. et al. Transtorno de estresse pós-traumático e uso de drogas ilícitas em mulheres encarceradas no Rio de Janeiro. Rev. psiquiatr. clín.São Paulo, v. 39,n. 2,p. 4347, 2012. Disponível em: <http://www.scielo.br/scielo.php?script=sci_arttext\&pid=S010160832012000200001\&lng=en\&nrm=iso >. Acesso em: 24 jan. 2016. http://dx.doi.org/10.1590/ S0101- 60832012000200001.

SOUZA, C. A. C. de. Doentes mentais em prisóes e em casas de custódia e tratamento: um grande e permanente desafio à psiquiatria e à Lei. Psiquiatria OnLine Brazil, v. 9, n. 12, dez. 2004. Disponível em: <http://www.hospitaldepsiquiatria.com.br/menu_03/artigos/art_007. htm>. Acesso em: 22 jan. 2016.

\section{Notas}

${ }^{1}$ Lei no 7.210 , de 11 de julho de 1984.

${ }^{2}$ Essa Portaria foi assinada pelos Ministérios da Saúde e Justiça

${ }^{3}$ Não há um direcionamento sistematizado por parte da Secretaria de Administração Penitenciária e Ressocialização da Bahia sobre quais ofertas de cuidado devem ser direcionadas para os usuários de SPA's, de modo que cada unidade prisional, a partir da equipe que a compóe, tenta, em maior ou menor medida, ofertar algum tipo de cuidado para essa populaçáo, a partir da negociação com a Coordenaçáo de Segurança e com os agentes penitenciários. Do mesmo modo, como é incomum a presença de um coordenador de saúde dentro das unidades prisionais, o trabalho desenvolvido tende a ser desarticulado, e não em equipe. Considerando a discrepância entre a política de Redução de Danos e o paradigma da segurança, calcado na lógica da abstinência, frequentemente o tema da RD era tido como de difícil abordagem pelos profissionais de saúde. 


\section{Abstract}

Care for drug users in deprivation of liberty This study aimed to identify the care offered to people who are imprisoned and on drugs, as well as the changes in mental health care following the publication of the National Health Plan in the Penitentiary System and the National Policy for Integral Health Care of Persons Deprived of Liberty. A bibliographic search was performed, and 129 articles were identified; six were selected after application of relevance tests. The literature points out that the use of drugs during sentence execution is consensual, despite the predominance of the prohibitionist paradigm to the detriment of harm reduction actions.

> Keywords: drug users; prisons; mental health; public policy. 